only on endoscopy of the small bowel; this operative technique was first described in $1975 .{ }^{4}$

Neither patient showed histological evidence of any known cause of intestinal ulceration, and neither had received potassium tablets for at least three years. Potassium tablets usually cause solitary and appreciably scarred ulcers. ${ }^{5}$ We do not think that the ulcers were caused traumatically during enteroscopy as we did not find any in two other patients investigated by this technique. Both our patients had underlying cardiac disease, and intestinal haemoperfusion may perhaps be so compromised in such patients that minimal changes in blood flow-for example, as a result of arterial spasm or microemboli-can produce transient mucosal ischaemia leading to focal haemorrhage and sloughing.

This type of ulceration may be more common than published reports indicate as it would not have been diagnosed in our two patients if they had not bled appreciably and undergone enteroscopy. We believe that these two patients showed a previously undescribed form of small-bowel ulceration that may be diagnosed only by enteroscopy, which should be available as a final test in the routine and emergency investigation of gastrointestinal bleeding.

We thank Dr I M Murray-Lyon for allowing us to report on a patient under his care.

${ }^{1}$ Anonymous. Idiopathic chronic ulcerative enteritis [Editorial]. Lancet 1982 ;ii:1118-9.

${ }^{2}$ Mills PR, Brown IL, Watkinson G. Idiopathic chronic ulcerative enteritis. Of Med $1980 ; 49: 133-49$.

${ }^{3}$ Spiller RC, Parkins RA. Recurrent gastrointestinal bleeding of obscure origin: report of 17 cases and a guide to logical management. Brf Surg $1983 ; 70: 489-93$

4 Bombeck CT. Intraoperative esophagoscopy, gastroscopy, colonoscopy and endoscopy of the small bowel. Surg Clin North Am 1975;55:135-42.

${ }^{5}$ Davies DR, Brightmore T. Idiopathic and drug-induced ulceration of the small intestine. Br F Surg 1970;57:134-9.

(Accepted 22 December 1983)

Gastrointestinal Unit and Department of Histopathology, Charing Cross Hospital, London W6

M J GLYNN, MB, MRCP, honorary senior registrar

J PENDOWER, MB, FRCS, consultant surgeon

S SHOUSHA, MD, MRCPATH, senior lecturer

R A PARKINS, MD, FRCP, consultant physician

Correspondence to: Dr M J Glynn, Gastrointestinal Unit, Charing Cross Hospital, London W6 8RF.

\section{Deficiency of medium chain fatty acylcoenzyme A dehydrogenase presenting as the sudden infant death syndrome}

Disorders of fatty acid metabolism due to deficiencies of several acylcoenzyme A dehydrogenases (glutaric aciduria, type $\mathrm{II}^{1}$ or to a more specific deficiency of a single acylcoenzyme A dehydrogenase ${ }^{2}$ have recently aroused great interest. These enzymes play a part in $\beta$ oxidation of fatty acids in mitochondria, and disorders resulting from their deficiency may present clinically as an illness resembling Reye's syndrome, manifesting the pathological changes seen in that syndrome. ${ }^{3}$ Deficiencies of acylcoenzyme A enzymes are thought to be inherited as an autosomal recessive trait.

We report on a boy, initially considered to be a victim of the sudden infant death syndrome, in whom pathological examination suggested Reye's syndrome. Subsequent evaluation, however, showed the absence of medium chain fatty acylcoenzyme A dehydrogenase as a single defect of mitochondrial enzymes.

\section{Case report}

An 18 month old boy started vomiting; this became more frequent with worsening, non-specific malaise and mild infection of the upper respiratory tract. Sixty hours later he suffered a grand mal convulsion and died. There was no relevant family history, and he was his parents' firstborn child.

Macroscopically, the brain was oedematous; the liver was pale but normal in size; and the nasopharynx was inflamed. Microscopic examination showed diffuse microvesicular fatty change without necrosis in cardiac and skeletal muscle, renal tubules, and the liver. No glycogen was detected in the liver.

Histochemical examination of frozen liver showed normal activities of cytochrome oxidase and succinic dehydrogenase. Homogenised frozen liver showed normal glutamate dehydrogenase activity. Activity of medium chain fatty acylcoenzyme A dehydrogenase was absent and activities of short and long chain dehydrogenases were moderately reduced when octanoyl, palmitoyl, and butyrylcoenzyme A respectively were used as substrates (table). Serum obtained from blood post mortem was analysed for organic acids by gas-liquid chromatography after discontinuous solvent extraction, and trimethyl silyl derivation showed the presence of octanoic acid. Two dimensional thin layer chromatography for amino acids did not show the presence of sarcosine. Post mortem vitreous humour glucose concentration was $0.2 \mathrm{mmol} / 1(3.6 \mathrm{mg} / 100 \mathrm{ml})$.

Activities of liver acylcoenzyme $A$ dehydrogenases to various substrates (expressed as $\mu \mathrm{mol}$ substrate/min/mg protein)

\begin{tabular}{ccc}
\hline Substrate & Patient & $\begin{array}{c}\text { Mean (SD) in controls } \\
(\mathrm{n}=5)\end{array}$ \\
\hline $\begin{array}{c}\text { Butyrylcoenzyme A } \\
\text { Octanoylcoenzyme A }\end{array}$ & $\begin{array}{c}0.98 \times 10^{-3} \\
\text { None detected } \\
0.19 \times 10^{4}\end{array}$ & $\begin{array}{c}2.27 \times 10^{3}\left(0.77 \times 10^{3}\right) \\
0.62 \times 10^{3}\left(0.87 \times 10^{\circ}\right.\end{array}$ \\
Palmitoylcoenzyme A & $\left.0.46 \times 10^{\circ}\right)$ \\
\hline
\end{tabular}

\section{Comment}

Diffuse fatty change in the liver of a severity similar to that found in Reye's syndrome was reported in 5\% of cases of the sudden infant death syndrome in one study, ${ }^{4}$ and the authors suggested that this might be associated with some unrecognised but specific disease process in a small proportion of these deaths. The case described here appears to belong to this group and would not have been diagnosed had the enzyme investigations not been carried out.

Reye's syndrome is probably a heterogeneous disorder, and certain metabolic disorders may mimic it. ${ }^{3}$ In Reye's syndrome there is preservation of cytoplasmic enzymes and, unlike in the present case, a reduction in most mitochondrial enzymes. ${ }^{5}$ The activities of short and long chain fatty acylcoenzyme $A$ dehydrogenases were moderately low in our patient (table), being $31 \%$ and $43 \%$ of the respective mean normal values. This may be explained by overlapping specificities of the three enzymes to the various substrates used. The absence of sarcosine suggests that our patient did not have a defect in the electron transfer chain distal to the dehydrogenase step.

Deficiencies in fatty acid acylcoenzyme $\mathbf{A}$ dehydrogenase enzymes are thought to be inherited in an autosomal recessive manner, and these inborn errors of metabolism may help to explain the slightly increased incidence of the sudden infant death syndrome in siblings of those who have already died of that syndrome. Screening of siblings is therefore indicated in families with a history of the sudden infant death syndrome. Gas-liquid chromatography of urine for organic acids is a simple way of detecting deficiencies in acylcoenzyme A dehydrogenase. These disorders may also be diagnosed antenatally by analysis of amniotic fluid cell enzymes and of liquor metabolites.

${ }^{1}$ Sweetman L, Nyhan WL, Trauner DA, Merritt TA, Singh M. Glutaric aciduria type II. $\mathcal{F}$ Pediatr 1980;96:1020-6.

2 Stanley CA, Hale DE, Coates PM, et al. Medium chain acyl-CoA dehydrogenase deficiency in children with non-ketotic hypoglycemia and low carnitine levels. Pediatr Res 1983;17:877-84.

${ }^{3}$ DeLong GR, Glick TH. Encephalopathy of Reye's syndrome: a review of pathogenetic hypotheses. Pediatrics 1982;69:53-63.

4 Sinclair-Smith CC, Dinsdale F, Emery JL. Evidence of duration and type of illness in children found unexpectedly dead. Arch Dis Child $1976 ; 51: 424-9$

${ }^{5}$ Mitchell AR, Ram ML, Arcinue EL, Chang $\mathrm{CH}$. Comparison of cytosolic and mitochondrial hepatic enzyme alterations in Reye's syndrome. Pediatr Res 1980;14:1216-21.

(Accepted 6 fanuary 1984)

\section{Children's Hospital, Sheffield S10 2TH}

A J HOWAT, MB, BS, senior registrar in pathology

M J BENNETT, PHD, senior biochemist

S VARIEND, MD, MRCPATH, consultant pathologist

Department of Biochemistry, University of Sheffield, Sheffield L SHAW, BSC, research assistant

Correspondence to: Dr A J Howat. 